\title{
Smart powder processing for energy and environment
}

\author{
M. Naito, H. Abe \& A. Kondo \\ Smart Processing Research Center, \\ Joining and Welding Research Institute, Osaka University, Japan
}

\begin{abstract}
Smart powder processing stands for novel powder processing techniques that create advanced materials with minimal energy consumption and environmental impacts. This process is also important from the viewpoint of sustainability. Particle bonding technology is a typical smart powder processing technique to make advanced composites. In this paper, its application examples for clean energy, energy-saving and novel recycling will be explained. For clean energy issues, the role of microstructure control of the electrodes for higher performance of Solid Oxide Fuel Cell (SOFC) by using particle bonding will be explained. From the viewpoint of energy-saving, a new method to produce fiber reinforced fumed silica compacts by making use of particle bonding will be introduced. It will be explained that the compacts have very low thermal conductivity with high porosity at high temperature. Furthermore, by carefully controlling the bonding between different kinds of materials, effective separation of elemental components can be achieved. It leads to the development of a novel technique for recycling advanced composite materials and turns them to high-functional applications. In this paper, its application for recycling of glass fiber reinforced plastics (FRP) will be explained.
\end{abstract}

Keywords: smart powder processing, particle bonding, nanoparticles, composite particles, energy-saving, recycling, SOFC, FRP.

\section{Introduction}

Smart powder processing stands for novel powder processing techniques that create advanced materials with minimal energy consumption and environmental impacts. This process is also important from the viewpoint of sustainability. 
Particle bonding technology is a typical smart powder processing technique to make advanced composites. The technology has two main unique features. Firstly, it creates direct bonding between particles without any heat support or binders of any kind in the dry phase. The bonding is achieved through the enhanced particle surface activation induced by mechanical energy, in addition to the intrinsic high surface reactivity of nanoparticles. Using this feature, desired composite particles can be successfully fabricated. The second feature of this technology is its ability to control the nano/micro structure of the assembled composite particles. As a result, it can custom various kinds of nano/micro structures and can produce new materials with a simpler manufacturing process.

Fig. 1 shows the examples of unique microstructure created by the particle bonding technique, which led to various kinds of applications. The a) of Fig. 1 shows SEM image of multi-layered composite particle for the drug delivery systems (DDS) [1]. The b) is a TEM photograph of tungsten carbide (WC) particles bonded by nano-sized platinum $(\mathrm{Pt})$ particles and carbon nanoparticles. By bonding these components to make composite catalyst, the amount of Pt used for Polymer Electrolyte Fuel Cell (PEFC) could be reduced down to about 25\% compared to that using commercially available $\mathrm{Pt} / \mathrm{C}$ catalyst [2].

The c) of Fig. 1 shows a SEM photograph of the anode microstructure of Solid Oxide Fuel Cell (SOFC) created by using composite particles as starting powder materials. In this paper, the role of microstructure control of the electrodes for higher performance of SOFC by using particle bonding process

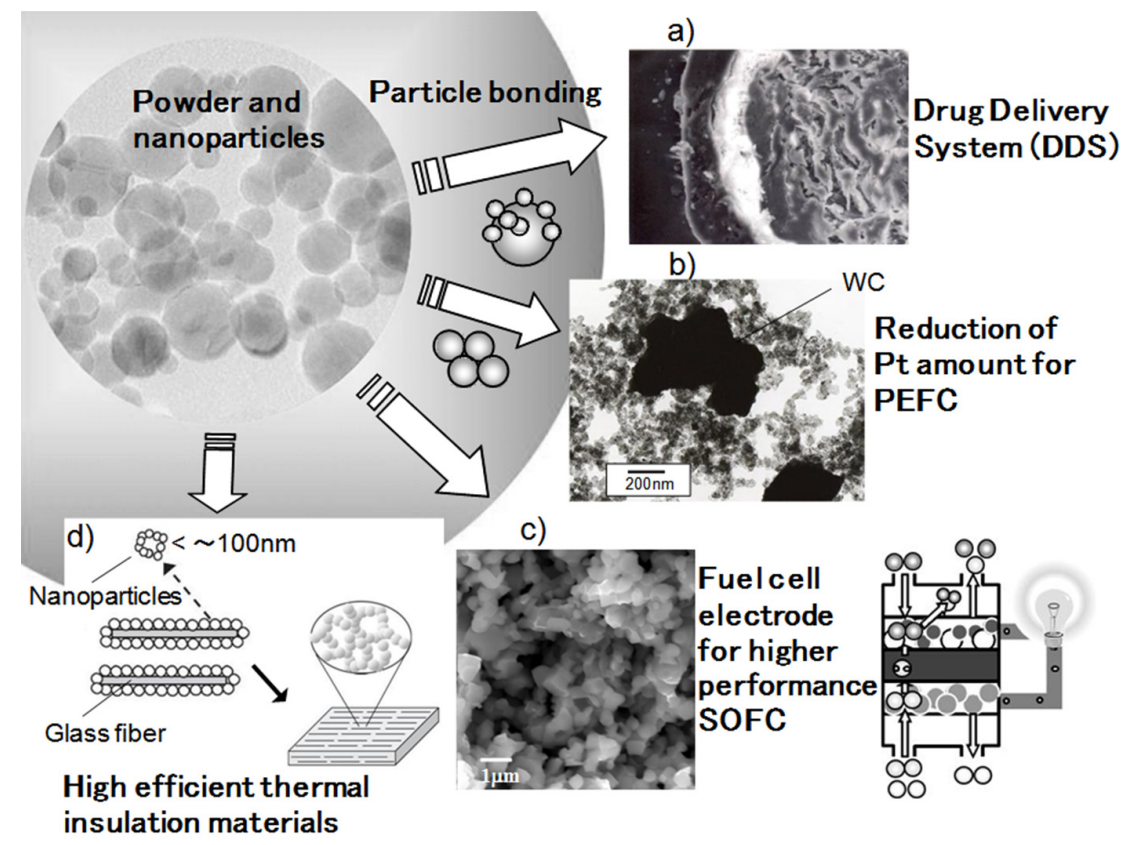

Figure 1: $\quad$ Unique microstructure created by particle bonding technique. 
will be explained. From the viewpoint of energy-saving, interest in thermal insulation materials has been globally, because escalating energy costs signified the importance of efficient thermal insulation. The d) of Fig. 1 shows a new method to produce fiber reinforced fumed silica compacts by making use of particle bonding $[3,4]$. In this paper, it will be explained that the compacts have very low thermal conductivity with high porosity at high temperature.

Furthermore, by carefully controlling the bonding between different kinds of materials, effective separation of elemental components can be achieved. It leads to the development of a novel technique for recycling advanced composite materials and turns them to high-functional applications. In this paper, its application for recycling of glass fiber reinforced plastics (FRP) will be explained $[5,6]$.

\section{Structural control of SOFC electrodes}

SOFC is a promising candidate for power generation in the 21 st century because of its high energy efficiency and clean exhaust. Current R\&D efforts focus on reducing its production cost and increasing the long-term stability of cells and stacks by lowering its operation temperature without losing power density. Prefabrication of the composite particles followed by electrode forming using particle bonding process is an ideal way to go, especially for controlling the microstructure of composite electrodes. Recently, we successfully fabricated various kinds of composite particles such as large core-particles coated with nanoparticles [7] and inter-dispersed composite mixture consisting of several kinds of nanoparticles using the particle bonding technique [8].

Nickel-yttria stabilized zirconia (Ni-YSZ) is the most widely used SOFC anode material due to its excellent electrochemical properties at high temperatures. The electrochemical reaction (hydrogen oxidation) takes place at the triple-phase boundary (TPB) where Ni, YSZ and fuel gas meet. The reaction rate strongly depends on the catalytic activity of anode materials and the TPB length. Since the former significantly decreases with decreasing operation temperature, the latter must be increased as much as possible in the limited effective electrode volume to keep high electrochemical performance even at lower temperatures. For the TPB enlargement, the anode microstructure such as size and arrangement of Ni and YSZ must be controlled precisely.

Fig. 2 shows the process to fabricate SOFC anode using coated composite particles, i.e. NiO large core-particle coated with YSZ nanoparticles [5]. The composite particles provided well-organized electrode microstructure as shown in the figure, and resulted in good electrochemical performance. As a result, a prototype SOFC power plant system with a capacity of about $1 \mathrm{~kW}$ was fabricated using the anode made by the coated composite particles and has been in services at an operating temperature of $700^{\circ} \mathrm{C}[5]$. 


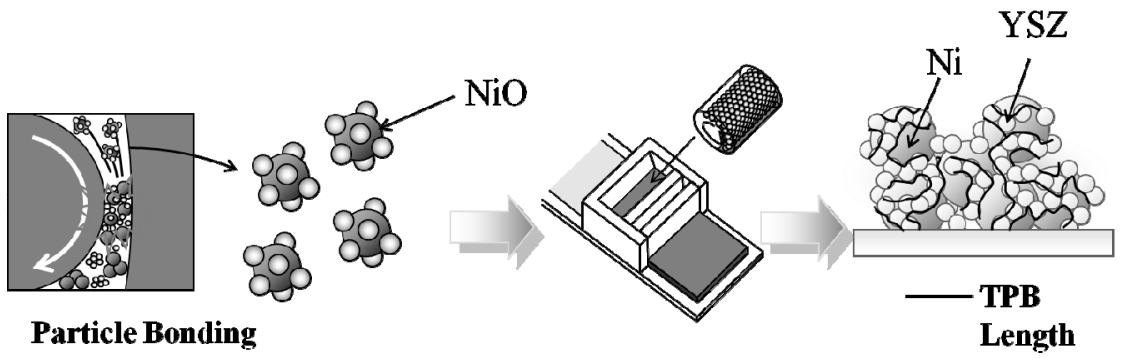

Figure 2: $\quad$ Unique microstructure created by particle bonding technique.

\section{Application of particle bonding for thermal insulation}

The second example is to make high efficient thermal insulation materials $[3,4]$. Interest in thermal insulation materials has been intensified globally, because escalating energy costs signified the importance of efficient thermal insulation. In this study, nanoparticle bonding process was used to make composite fibers coated with porous fumed silica layer in the dry phase. Fig. 1 d) shows the proposed dry processing method to fabricate fumed silica compact by using composite fibers [3]. Fiber glass composites porously coated with silica nanoparticles were fabricated at the first stage and then compacted into a board by dry pressing. The composites were produced by a particle bonding process without collapsing the fiber glass and nano-scale pores made by the fumed silica. The proposed method had the advantage of preventing contacts between fibers in the compacts due to the existence of coating layer. In addition, since fumed silica was fixed on the fibers, particle segregation rarely occurred during forming. Therefore, highly uniform dispersion of fibers in the compact could easily be achieved.

Table 1: Thermal conductivity of the fibrous fumed silica compacts prepared by particle bonding process.

\begin{tabular}{|c|c|c|c|c|}
\hline \multirow[t]{2}{*}{ Specimen } & \multirow[t]{2}{*}{$\begin{array}{l}\text { Density } \\
{\left[\mathrm{kg} / \mathrm{m}^{3}\right]}\end{array}$} & \multirow[t]{2}{*}{$\begin{array}{c}\text { Porosity } \\
\text { [\%] }\end{array}$} & \multicolumn{2}{|c|}{$\begin{array}{c}\text { Thermal Conductivity } \\
{[\mathrm{W} /(\mathrm{m} \cdot \mathrm{K})]}\end{array}$} \\
\hline & & & (a) $100^{\circ} \mathrm{C}$ & (a) $400^{\circ} \mathrm{C}$ \\
\hline A & 459 & 81.2 & 0.0266 & 0.0269 \\
\hline B & 485 & 80.1 & 0.0266 & 0.0282 \\
\hline
\end{tabular}

Table 1 shows the thermal conductivity of compact specimens with $80 \%$ porosity at $100^{\circ} \mathrm{C}$ and $400^{\circ} \mathrm{C}$ [3]. They were lower than molecular conductivity of still air $\left(0.03 \mathrm{~W} / \mathrm{mK}\right.$ at $100^{\circ} \mathrm{C}, 0.05 \mathrm{~W} / \mathrm{mK}$ at $\left.400^{\circ} \mathrm{C}\right)$ and at the same level as those obtained from silica aerogel and fumed silica compacts. These results indicated that the obtained compacts had nano-scale porous structure. The remarkable attribute of composite fibers was achieving very low thermal 
conductivity with a relatively large amount of glass fibers. Mechanical strength of the compacts depends on their apparent density determined by the compressive strength. In this case, fracture strength ranged from 0.4 to $1.6 \mathrm{MPa}$, corresponding to apparent densities from 400 to $480 \mathrm{~kg} / \mathrm{m}^{3}$, could be obtained. This made it possible to machine the compacts for various applications.

The present study demonstrated that the dry powder processing method as shown in Fig. 1d) provided fibrous fumed silica compacts with mechanical reliability and efficient thermal insulation. The specific feature of this method was to apply effective mechanical processing for making fumed silica fiber composites, instead of conventional mixing techniques. The powder mixture consisting of composite fibers was in a good mixing state and resulted in fumed silica compact with well-dispersed fibers. The existence of fumed silica layer on the glass fiber could prevent direct fiber-fiber contacts in the compact which avoided solid thermal transport through the fibers even at high fiber loadings. Thus, as mentioned above, fumed silica compacts with efficient thermal insulation and good mechanical strength were achieved in this study [3].

Furthermore, the thermal conductivity of fumed silica compacts at higher temperature could also be kept at lower value by adding $\mathrm{SiC}$ powders as an opacifier. It was found that thermal insulation compacts made of powder mixture consisting of fumed silica: glass fiber: $\mathrm{SiC}$ at a mass ratio of 70:10:20 prepared by the particle bonding technique could achieve a thermal conductivity of $0.04 \mathrm{~W} / \mathrm{mK}$ at $600^{\circ} \mathrm{C}$ [9]. By changing the kind of nanoparticle additives, it was expected that thermal conductivity of the compacts could be kept lower at even higher temperatures by particle bonding process in the future.

\section{Novel recycling for lower energy and sustainability}

Fig. 3 shows the concept of smart recycling of composite materials by using the particle bonding and disassembling between different kinds of materials [5]. From the conventional recycling standpoint of view, each element of waste composite material must be returned back to its original state for repeated usage. It is acceptable when the purpose of the recycling is to recover only valuable element from the waste materials. However, it needs high recycling costs and the obtained element has lower quality than the virgin material. As a result, the recycling process cannot be practically used. On the contrary, the proposed recycling concept does not aim to obtain each original element, but develops further advanced materials using disassembled blocks of the waste composite materials. In this case, how to apply bonding and disassembling the waste materials is the very key issue. As shown in Fig. 3, recycling waste back to its intermediate structure and then assembling it with another material to make further advanced materials would be more energy efficient than reclaiming the original elements. This concept will be a basis for the next generation of recycling system for advanced materials. In this paper, an approach to recycle glass fiber reinforced plastics (FRP) will be explained as follows:

FRP is a typical composite material having the advantages of lightweight, high strength and high weather resistance. Therefore, it has been used in various 
applications including boats, bath tubs, and building materials. Its production volume reached 460,000 tons in Japan in 1996, but decreased gradually since then. However, the volume of waste FRP has increased every year. So far, almost all of the waste FRP has been incinerated or disposed in landfill. Only $1-2 \%$ of the waste FRP is recycled as cement raw material or additives for concrete. Japan Reinforced Plastics Society started producing cement recycled from FRP in 2002. The incineration of FRP has problems of low calorific values on burning, and its residue needs to be disposed.

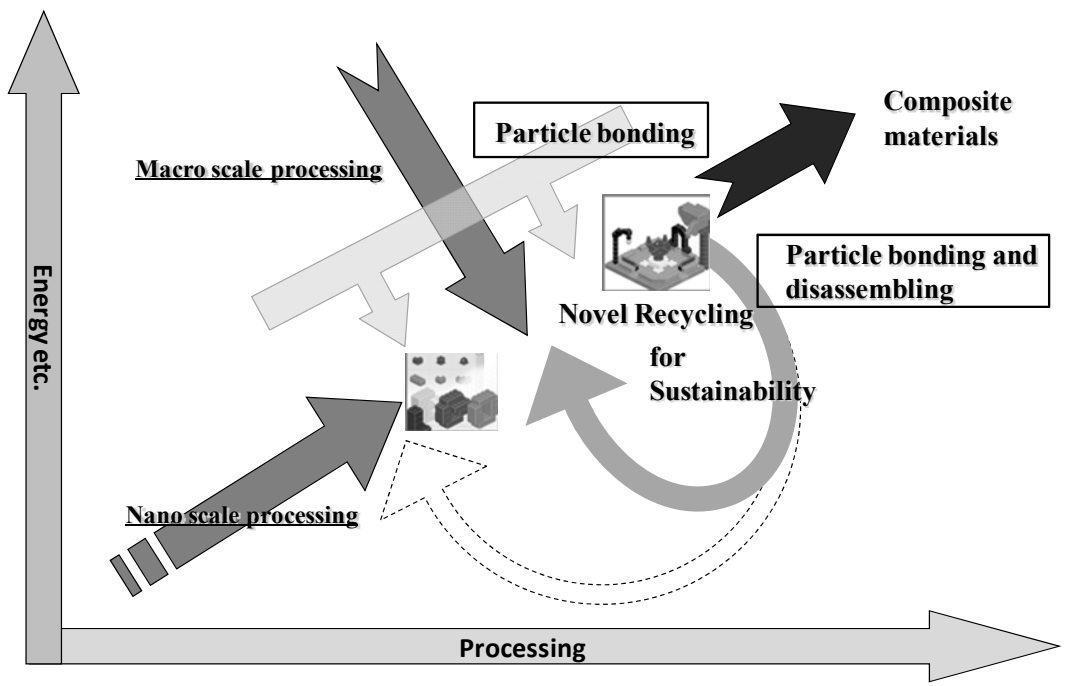

Figure 3: Concept of smart recycling for composite materials based on particle bonding principle.

FRP usually contains $40-50 \%$ of calcium carbonate filler and $20-30 \%$ of glass fibers. These materials must be recycled through simple and low energy process for profits. Therefore, we aimed to develop new recycling method to make advanced materials from the waste FRP based on the concept as shown in Fig. 3. Fig. 4 shows the concept of an innovative recycling process of FRP proposed by the authors [5]. It consisted of two unit processes. First, FRP was separated into glass fibers and matrix resins, and then, the surface of separated glass fibers was coated by low cost nanoparticles. The coated composite glass fibers would be compacted to make porous materials as shown in Fig. $1 \mathrm{~d}$ ). High functional materials having the properties of very low thermal conductivity, light weight, and easy machining are expected to obtain by applying the new process shown in Fig. 1 d).

The waste FRP chip crushed down to about $1 \mathrm{~cm}$ was processed by an attrition-type mill, which applied similar mechanical principle to that of particle bonding process. When strong shear stress was applied to the chip layers for surface grinding, glass fibers began to separate from matrix resins on the chip surfaces. As a result, all glass fibers were effectively separated from other matrix components. 


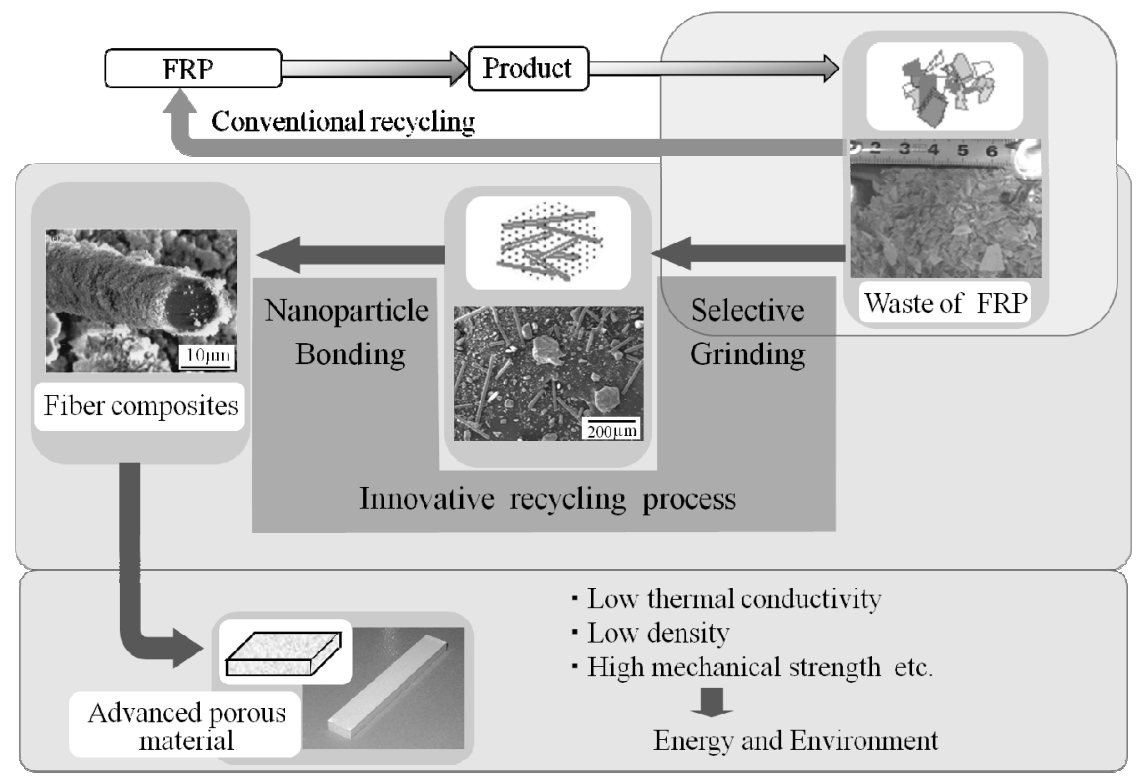

Figure 4: $\quad$ Smart recycling process of FRP.

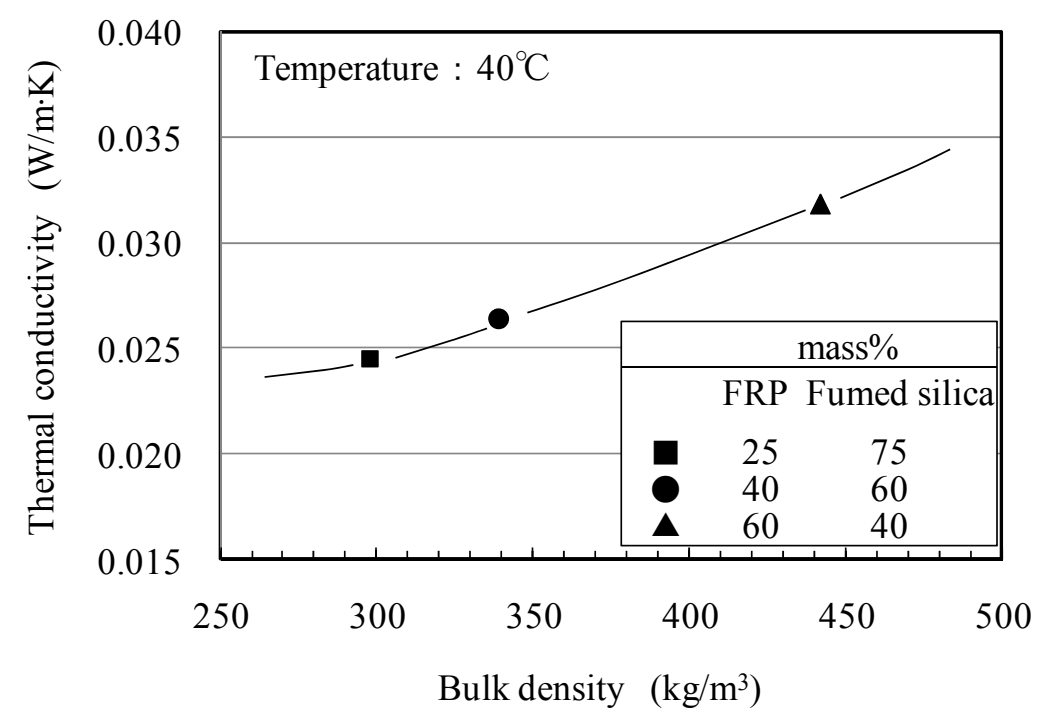

Figure 5: Relationships between thermal conductivity and bulk density of the compacts.

Then, the surface of glass fibers and that of matrix components were mechanically bonded with nanoparticles. Fig. 4 shows the glass fiber composite particles coated with fumed silica nanoparticles. It shows that the surface is 
covered by nanoporous layer. The board was compacted with the mixture of glass fiber composites and matrix components by dry pressing. The board has relatively high fracture strength. Therefore, it was easy for machining into various shapes.

Fig. 5 shows the relationship between thermal conductivity and bulk density of the compact [9]. When fumed silica mass percentage increases, the bulk density decreases, thus leads to extremely lower thermal conductivity of the compact as shown in Fig. 5. These results suggest that the board will be used as a new material such as building material in the future.

\section{Conclusions}

In this paper, particle bonding process was explained as a typical example of smart powder processing. This process enabled us to develop new composite materials. Based on its principle, the electrodes for SOFC and the high performance thermal insulator were developed. This process is also applicable for new recycling process for waste composite materials. By using this process, the waste materials will be turned into other advanced materials. It is believed that dry particle bonding technology can open the doors for various kinds of smart powder processing applications in the future.

\section{References}

[1] Fukumori, Y., Ichikawa, H., Uemura, T., Sato, K., Abe, H. \& Naito, M., Process performance of dry powder coating for preparing controlled release microcapsules by a High speed mixer. Proceedings of 8th International Symposium on Agglomeration, Bangkok, Thailand, March 16-18, pp. 31-38, 2005.

[2] Munakata, H., Tashita, T., Kanamura, K., Kondo, A. \& Naito, M., Development of low-platinum catalyst for fuel cells by mechano-chemical method. J. Soc. Powder Technol., Japan, 48(6), in press, 2011.

[3] Abe, H., Abe, I., Sato, K. \& Naito, M., Dry powder processing of fibrous fumed Silica compacts for thermal insulation. J. Am. Ceram. Soc., 88, pp. 1359-1361, 2005.

[4] Abe, I., Sato, K., Abe, H. \& Naito, M., Formation of porous fumed silica coating on the surface of glass fibers by a dry mechanical processing technique. Advanced Powder Technology, 19, pp. 311-320, 2008.

[5] Naito, M., Abe, H., Kondo, A., Yokoyama, Y. \& Huang, C.C., Smart powder processing for advanced materials. KONA Powder and Particle Journal, 27, pp. 130-141, 2009.

[6] Kondo, A., Abe, H., Isu, N., Miura, M., Mori, A., Ohmura, T. \& Naito, M., Development of light weight materials with low thermal conductivity by making use of waste FRP. J. Soc. Powder Technol., Japan, 47, pp. 768-772, 2010 . 
[7] Fukui, T., Murata, K., Ohara, S., Abe, H., Naito, M. \& Nogi, K., Morphology control of Ni-YSZ cermet anode for lower temperature operation of SOFC. J. Power Sources, 125, pp. 17-21, 2004.

[8] Sato, K., Abe, H., Misono, T., Murata, K., Fukui, T. \& Naito, M., Enhanced electrochemical activity and long-term stability of Ni-YSZ anode derived from NiO-YSZ interdispersed composite particles. J. European Ceram. Soc., 29, pp. 1119-1124, 2009.

[9] Ohmura, T., Abe, I., Ito, Y., Sato, K., Abe, H. \& Naito, M., Development and evaluation of characteristics of nanoporous materials. J. Soc. Powder Technol., Japan, 46, pp. 461-466, 2009. 